\title{
Tourism persistence in Spain: National versus international visitors
}

Tourism Economics

$1-12$

(C) The Author(s) 2019

Article reuse guidelines: sagepub.com/journals-permissions DOI: $10.1177 / 1354816619891349$ journals.sagepub.com/home/teu

@SAGE

\section{Luis A Gil-Alana}

University of Navarra, Spain; Universidad Francisco de Vitoria, Spain

\author{
Águeda Gil-López \\ Universidad Francisco de Vitoria, Spain
}

Elena San Román

Complutense University, Spain

\begin{abstract}
In this article, we examine the statistical properties of the time series corresponding to the number of national and international visitors in Spain using fractional integration. This methodology allows us to examine the degree of persistence of the series, and thus, infer some conclusions about the nature of the shocks. According to the results reported in this work, seasonality matters in both cases, being more important in international tourism. Moreover, we observe significant differences in the degree of persistence between national and international tourism. Although both series seem to be mean reverting, with shocks having a transitory nature, higher orders of integration are observed in the case of the international arrivals.
\end{abstract}

\section{Keywords}

international tourism, national tourism, persistence, seasonality, Spain

\section{Introduction}

This article investigates statistical properties of the number of visitors to Spain, separating the data into national and international travelers and investigating, in particular, the degree of dependence in the data by using fractional integration. This methodology is very flexible and general, and includes the two standard cases of stationarity and nonstationarity or unit roots as specific cases when the orders of integration are respectively 0 and 1 . However, it is well known that, in 
aggregated data, the order of integration can be a fractional value, constrained between 0 and 1 , or even above 1. This allows us to examine the series in a more flexible way permitting, for example, stationary and nonstationary mean reverting processes with long-lasting effects of shocks.

There are in fact numerous articles that have used this methodology of fractional differentiation in the context of tourism time series, in contrast to the use of conventional unit root tests or the univariate time series models, such as autoregressive moving average (ARIMA) or seasonal ARIMA (SARIMA) (Cho, 2003; Goh and Law, 2002; Lean and Smyth, 2008, 2009; Liang, 2014; Tang, 2011; among others). For example, Gil-Alana et al. (2004) applied a seasonal fractional integration method, focused on Spanish inbound tourism, and found that there is seasonal long memory behavior. The present article differs from that one in several aspects: firstly, the data frequency used, being quarterly in Gil-Alana et al. (2004) and monthly in the present case. Secondly, the sample is also different being from 1965q1 to 2002q4 in the former case and from $2001 \mathrm{~m} 1$ to $2018 \mathrm{~m} 10$ in our case. Finally, the methodology used is also different, and though in both cases long memory processes are used, in Gil-Alana et al. (2004) the approach employed is based on a seasonally fractionally integrated model that uses polynomials of the form $\left(1-L^{4}\right)^{d}$, while in the present work seasonality is captured throughout a seasonal autoregressive (AR(1)) process and the long memory feature involves polynomials of the form $(1-\mathrm{L})^{\mathrm{d}}$. Dealing with the seasonality issue, Gil-Alana (2005) also applied long memory to examine the forecasting properties of data referring to arrivals in New Zealand and finds that the seasonal models outperform the nonseasonal ones. Apergis et al. (2017), using a variety of specifications, found that a seasonal ARIMA model with Fourier transformation outperforms other alternative models in terms of its forecasting properties. In Gil-Alana et al. (2015), however, seasonality in Croatian tourism is examined in terms of seasonal unit roots, and seasonal differentiation is adopted prior to the analysis of the series. The same evidence in favor of seasonal unit roots is found in another paper by the same authors (Gil-Alana et al., 2016) using also Croatian tourism data.

Box-Steffensmeier and Tomlinson (2000) and Zivot and Wang (2007) showed the advantages of fractional differentiation over conventional integer differentiation or unit roots models, suggesting that this method enables the degree of dependence or memory of the series to be examined in a more flexible way. Cunado et al. (2008a) deal with the analysis of the US total number of international monthly arrivals, and using a long memory fractionally integrated model that allows the inclusion of a single break endogenously determined by the model, they found that the degrees of integration of all the series are significantly below 1 and thus showing a mean reverting pattern. In a related paper, Cunado et al. (2008b) also investigated the long memory feature in the monthly arrivals to the Canary Islands. They used a model that, along with fractional differentiation, contains seasonal autoregressions, showing values for the differencing parameter which are slightly above 0.5 . Similar evidence in favor of persistence and mean reversion is found in GilAlana and Payne (2018) for the international tourist arrivals in the United States, and they also found that the degree of persistence seems to have increased in the post-September 2001 period. Assaf et al. (2011) also found long memory in tourism data for the case of Australia; Nowman and Van Dellen (2012) with UK data; Chen and Malinda (2014) for the returns of travel and tourism indexes in Taiwan; and Al-Shboul and Anwar (2017) for Singapore. Gil-Alana and Huijbens (2018) also applied fractional integration to analyze tourism seasonality and the impact of exogenous shocks in Iceland. Indeed, seasonality is a relevant feature of tourism demand and it cannot be ignored when modeling processes using these type of data (Gil-Alana et al., 2014; Song and Li, 2008; etc.). 
Following the above line of research, this article also focuses on fractional integration, examining tourism in Spain and distinguishing between international and national tourism. This study offers two main contributions. First, we show that both series corresponding to national and international tourists in Spain are highly seasonal and persistent. Second, we show that the degree of integration is higher in the case of international visitors, which means that shocks in this latter series have long-lasting effects.

The rest of the article is structured as follows: the second section briefly reviews the recent evolution of tourism in Spain. The third section briefly describes the fractional integration or I(d) approach used in the article. The fourth section presents the data and displays the main empirical results, while the fifth section contains some discussion and concluding comments.

\section{Tourism in Spain}

Tourism is a relevant activity for the Spanish economy. In 2017, it accounted for $11.7 \%$ of gross domestic product (GDP), and generated 2.60 million jobs which represented $12.8 \%$ of total employment (INE, 2018). Moreover, Spain is the second country in the world in terms of tourist revenues, after the United States, and ranks the third in relation with the number of tourist arrivals, after France and the United States (UNWTO, 2018).

From a historical perspective, Spain underwent a delayed incorporation to international tourism. Indeed, the Spanish tourism industry did not really begin to expand until the 1950s thanks to the combination of growing economic openness, the progressive integration of Spain into the international economy as well as the economic recovery of the United States and Western Europe, which brought about the beginning of mass tourism, a demand which Spain was well-placed to satisfy (San Román, 2017; Vallejo-Pousada, 2013). Since the early 1960s, tourism revenues and contribution to GDP have been steadily growing thereby turning Spain into a world tourism power. Indeed, Spain's share in world tourism income rocketed from a mere $0.8 \%$ in 1950 to slightly more than 7\% in 2001 (Banco de España, 2004; Vallejo-Pousada, 2013).

Yet, Spanish tourism has not been exclusively external. Domestic tourism has also had a relevant contribution to the Spanish economy (Gálvez et al., 2014). However, one of the singularities of Spain compared to other tourism leaders has been the relatively high contribution of nonresidents to total tourist income. The net contributions of inbound tourism to the economy has been, in the Spanish case, higher than that of its most direct Mediterranean competitors (France or Italy) and outbound and internal tourism have developed much later in Spain.

By the beginning of the 21st century, tourism in Spain was already a consolidated sector. Yet, figures continued to show a growth trend, as illustrated in the first two plots of Figure 1. Between 2001 and 2018, the number of international visitors in Spain increased from 75 million to 124 million (FRONTUR, INE). The economic recession that affected some of the Spain's main target market populations (United Kingdom, France, and Germany) resulted in a drop between 2008 and 2011. Since then, international tourism growth has been especially remarkable, partly due to the revolutions in the Arab world, which made tourists switch their holidays from these countries to Spain, and the fall of salaries - in real terms - which helped restore Spain's eroded competitiveness.

In contrast to foreign visitor trends, Spanish domestic tourism experienced a more limited expansion during the 21st century, as illustrated in the first plot of Figure 1. In 2018, the number of trips made within Spain by Spanish residents amounted to 178 million, which represented $29 \%$ more than in 2001 (FAMILITUR, INE). However, that expansion mostly corresponds to the period 

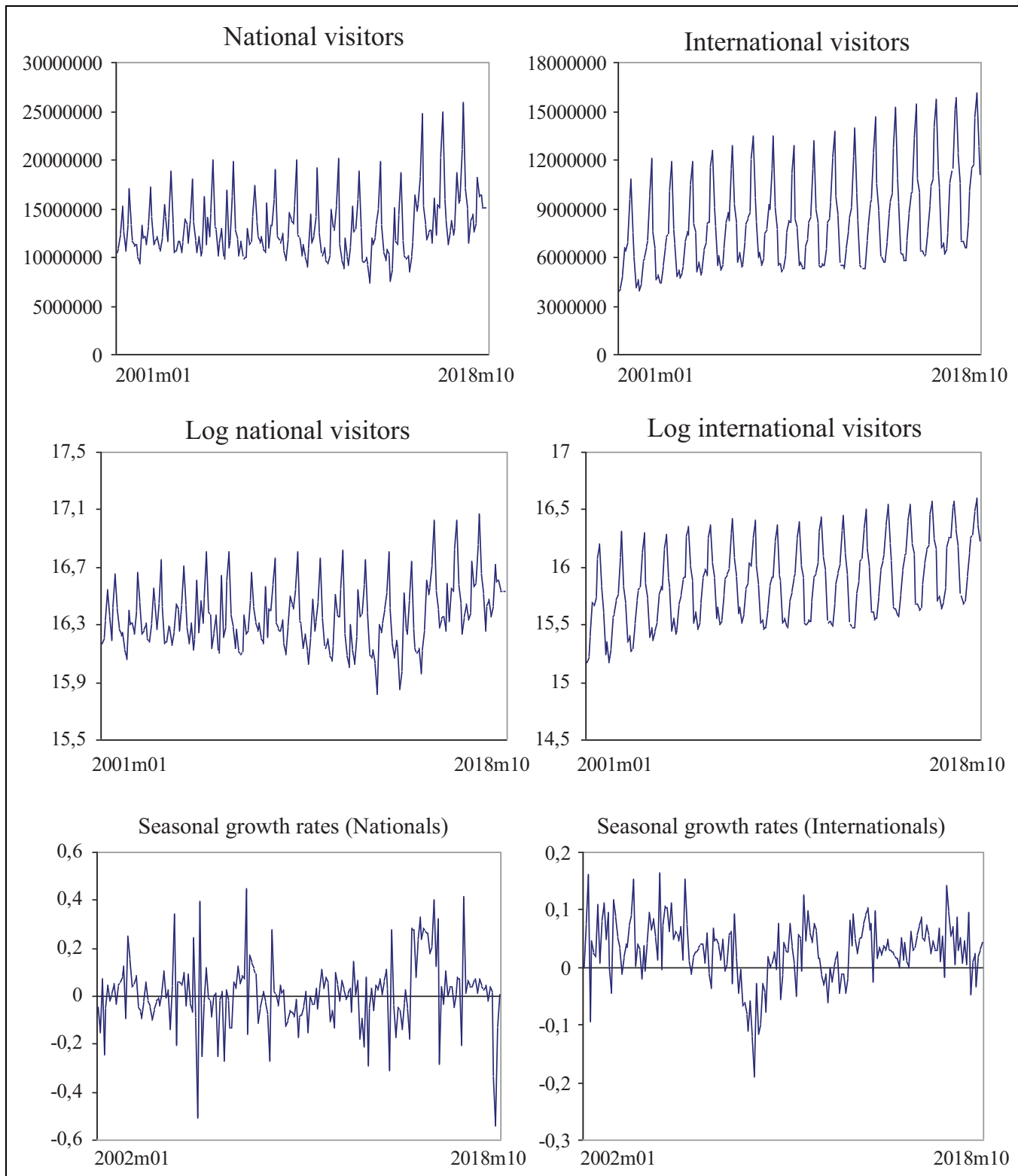

Figure I. Time series plots.

since 2014 onward, when the economic recovery of Spain was a catalyst to the increasing dynamism of domestic tourism, after the downturn registered between 2008 and 2014.

The importance of tourism in Spain explains why numerous studies have focused on this destination, drawing on different approaches, both quantitative and qualitative. Regarding 
econometric studies, González and Moral (1995, 1996) used structural time series model to examine the evolution of the international tourism demand in Spain and forecast its trends. Similarly, Garcia-Ferrer and Queralt (1997) employed structural time series to investigate if price and income variables may help forecast tourism demand in Spain. Rosselló-Nadal (2001) drew on the leading indicator approach to analyze the British and German tourist behavior in the Balearic Islands, while Medeiros et al. (2008), also focusing on tourism arrivals in this Spanish region, employed a neural network forecasting model incorporating time-varying conditional volatility.

Cunado et al. (2005) focused on the issue of seasonality in the analysis of Spanish tourism, and for this purpose they used a model that includes both deterministic seasonality (based on seasonal dummies) and stochastic seasonality (with integer and fractional orders of integration). Their results indicate that the tourism time series for Spain can be well described in terms of seasonally fractionally differenced models. Cunado et al. (2008b) examined the level of dependence in international monthly arrivals to the Canary Islands using a model that combined fractional differentiation with seasonal AR processes. They showed that the series can be well described in terms of an $\mathrm{I}(\mathrm{d})$ model with the value of $\mathrm{d}$ being slightly above 0.5 . Gil-Alana et al. (2008) analyzed the number of tourists arriving to the Canary Islands and compared the use of different statistical seasonal models. Garín-Muñoz (2011) studied British tourism demand behavior by employing panel data and dynamic models including economic variables and the demand in the previous period. Lopez et al. (2017) compared global forecast passenger air traffic results using SARIMAX models with the addition of individual models results by airport, while Landaluce-Calvo (2017) used a multivariate exploratory analysis to describe the temporal structures of the evolution of the tourist demand.

\section{Methodology}

As earlier argued in above sections, this article focuses on fractional differentiation which implies that the order of integration of a series, that is, the number of differences required in that series to render it stationary $\mathrm{I}(0)$ is not an integer but a fractional value. In other words, we say that a given time series $\left\{x_{t}, t=1,2, \ldots,\right\}$ is integrated of order $\mathrm{d}$, and denoted as $x_{t} \approx \mathrm{I}(\mathrm{d})$, if it can be represented as

$$
(1-B)^{\mathrm{d}} x_{t}=u_{t}, \quad t=1,2, \ldots,
$$

where $B$ is the back-shift operator (i.e. $B^{k} x_{t}=x_{t-k}$ ); d can be any real value, and $u_{t}$ is $\mathrm{I}(0)$, that is, second-order (or covariance) stationary and with a spectral density function that is positive and bounded at any frequency across the spectrum. In other words, $u_{t}$ can be an uncorrelated process, that is, a white noise process, but may also include (weak) autocorrelation, for instance, of the autoregressive moving average (ARMA) type. Thus, for example, if $u_{t}$ is an ARMA(p, q) process, then, $x_{t}$ is said to be fractionally integrated ARMA or autoregressive fractionally integrated moving average (ARFIMA) ( $\mathrm{p}, \mathrm{d}, \mathrm{q})$ process.

The estimation of $d$ is crucial since different conclusions can be obtained depending on the range of this value. Thus, if $\mathrm{d}=0$, the series is integrated of order $0, \mathrm{I}(0)$, also named short memory, contrary to the case of long memory that takes place as long as $d>0$. Moreover, if $d$ belongs to the interval $(0,0.5)$, the series is still covariance stationary though belonging to the long memory category; if $0.5 \leq \mathrm{d}<1$, the series is no longer stationary but is still mean reverting, with the effect of the shocks being long-lasting though disappearing in the long run; finally, if $d \geq 1$, the series is not mean reverting, with shocks having permanent effects. ${ }^{1}$ 
For the estimation of the differencing parameter d, we employ the Whittle method in the frequency domain (Dahlhaus, 1989) by using a Lagrange multiplier method described in Robinson (1994). This method is very convenient, firstly, because it is valid for any range of values of $d$, including stationary (i.e. values of $\mathrm{d}$ below 0.5$)$ and nonstationary $(\mathrm{d} \geq 0.5)$ regions. Moreover, it has a standard $\mathrm{N}(0.1)$ limit distribution, and this normal limit behavior holds independently of the inclusion of deterministic terms such as intercepts and/or linear trends. Finally, it is found to be the most efficient method in the Pitman sense against local departures from the null. Its functional form can be found in some of the empirical works conducted using this method (e.g. Abbritti et al., 2016; Gil-Alana, 2000; Gil-Alana and Henry, 2003; Gil-Alana and Robinson, 1997; Yaya et al., 2015; etc.).

\section{Data and empirical results}

Monthly data corresponding to the number of national and international visitors in Spain between January 2001 and October 2018 are used in this work. Data were collected from three main sources: (i) Spanish National Statistics Institute (INE), the official agency in Spain that collects and publishes statistics about Spanish demography, society, and economy; (ii) the statistical operation FAMILITUR "Movimientos Turísticos de los Españoles" ("Tourist Movements of the Spanish"); and (iii) the statistical data FRONTUR "Movimientos Turísticos en Fronteras" ("Tourist Movement on Borders"). Both FAMILITUR and FRONTUR statistics are provided by the Spanish National Tourist Office (TURESPAÑA).

National visitors are measured by the number of trips made by Spanish residents within the borders of Spain. Data between January 2001 and January 2015 were collected from FAMILITUR. Data since February 2015 come from the Spanish INE. On the other hand, international visitors include both tourists and "same-day visitors" or excursionists. A visitor is defined as "a traveler taking a trip to a main destination outside his/her usual environment, for less than a year, for any main purpose (business, leisure or other personal purpose) other than to be employed by a resident entity in the country or place visited. A visitor is classified as a tourist (or overnight visitor), if his/ her trip includes an overnight stay, or as a same-day visitor (or excursionist) otherwise" (UNWTO, 2014: 13). Data on international visitors between January 2001 and September 2015 were collected from FRONTUR, whereas data since October 2015 come from the Spanish INE.

Following standard parameterization of deterministic terms in unit root models (Schmidt and Phillips, 1992), we examine the regression model

$$
y_{t}=\beta_{0}+\beta_{1} t+x_{t}, \quad t=1,2, \ldots,
$$

where $y_{t}$ refers to each of the observed time series, $\beta_{0}$ and $\beta_{1}$ are unknown coefficients referring respectively to an intercept and a linear time trend, and $x_{t}$ is by assumption $\mathrm{I}(\mathrm{d})$ as defined in equation (1). Moreover, taking into account the monthly nature of the series considered, we allow for a seasonal $\mathrm{AR}(1)$ process for the disturbance term, such that $u_{t}$ in (1) is specified as

$$
u_{t}=\varphi u_{t-12}+\varepsilon_{t}, \quad t=1,2, \ldots,
$$

where $\varepsilon_{t}$ is supposed to be a white noise process. Thus, the estimated model is

$$
y_{t}=\beta_{0}+\beta_{1} t+x_{t}, \quad(1-B)^{\mathrm{d}} x_{t}=u_{t}, \quad u_{t}=\varphi u_{t-12}+\varepsilon_{t}
$$

Table 1 displays the estimated values of $d$ in the model in (4) for three potential setups: (i) including no terms in the first equality in (4) (i.e. $\beta_{0}=\beta_{1}=0$ a priori in (4)), (ii) including a 
Table I. Estimates of $d$ on the logged series.

\begin{tabular}{|c|c|c|c|}
\hline Log series & No regressors & An intercept & A linear trend \\
\hline National & $0.98(0.89,1.08)$ & $0.18(0.11,0.27)$ & $0.15(0.07,0.26)$ \\
\hline International & $0.98(0.89,1.09)$ & $0.76(0.47,0.93)$ & $0.78(0.62,0.92)$ \\
\hline
\end{tabular}

Note: The values are the estimates of $d$ using Robinson (1994). Those in parenthesis are the $95 \%$ confidence bands, and in bold, the selected models across the deterministic terms.

Table 2. Estimated coefficients on the selected models in Table I.

\begin{tabular}{lcccc}
\hline Log series & $d$ & Intercept & Linear time trend & Seasonal AR \\
\hline National & $0.15(0.07,0.26)$ & $16.283(16.36)$ & $2.077(573.48)$ & 0.760 \\
International & $0.76(0.47,0.93)$ & $15.295(76.55)$ & - & 0.968 \\
\hline
\end{tabular}

Note: In parenthesis in columns 3 and 4, their corresponding $t$-values.

constant ( $\beta_{1}=0$ and $\beta_{0}$ estimated), and (iii) including both a constant and a linear time trend (both $\beta_{0}$ and $\beta_{1}$ estimated from the data).

We have represented in bold in Table 1 the selected model for each series according to these deterministic components. ${ }^{2}$ We observe that for the national visitors a linear trend is required, but for the international ones, an intercept seems to be sufficient to describe the deterministic part. Table 2 displays all the estimated coefficients. We see that $d$ is equal to 0.15 for the nationals and 0.76 for the internationals. In both cases, the confidence bands reject the hypothesis of $d=0$ and $d$ $=1$, supporting thus the case of fractional integration; however, we obtain evidence of stationarity $(d<0.5)$ for the national visitors but nonstationary $(\mathrm{d} \geq 0.5)$ for the international ones, and evidence of mean reversion $(\mathrm{d}<1)$ in the two cases. Finally, we observe that the seasonal AR coefficients are 0.760 and 0.968 , respectively, for national and international visitors.

Based on these large values for the estimates of the seasonal component, we next perform seasonal unit root tests in the two cases. In particular, we conduct Dickey et al. (DHF, 1984) and Hylleberg et al. (HEGY, 1990) in the two series and the results strongly support the hypothesis of unit roots in the two cases. Thus, in what follows, we focus on the first seasonally differenced series, corresponding to the seasonal growth rates. Plots of the series are given in the lower part of Figure 1.

Table 3 reports the estimates of $d$ in a model given by equations (1) and (2), that is

$$
y_{t}=\beta_{0}+\beta_{1} t+x_{t}, \quad(1-B)^{\mathrm{d}} x_{t}=u_{t}, \quad t=1,2, \ldots,
$$

where $y_{t}$ is now the seasonal growth rate series, and assuming that the error term $u_{t}$ is first a white noise process, and then allowing for weak autocorrelation of the Bloomfield (1973) form. This is a model which is only implicitly determined by its spectral density function but that generates autocorrelations decaying at an exponential rate as in the ARMA case. ${ }^{3}$

Starting with the case of no autocorrelation we observe that the estimates of $\mathrm{d}$ are now 0.14 (nationals) and 0.30 (internationals), implying mean reverting and stationarity in both cases, and, allowing for autocorrelation the values are slightly higher, 0.46 and 0.60 . Thus, once more, evidence of mean reverting patterns is obtained in the two series and the values are higher for international than for national visitors. 
Table 3. Estimates of $d$ on the first seasonally differenced series.

(i) No autocorrelation

\begin{tabular}{lccc}
\hline Seasonal growth res. & No regressors & An intercept & A linear trend \\
\hline National & $0.14(0.07,0.23)$ & $\mathbf{0 . 1 4}(\mathbf{0 . 0 7}, \mathbf{0 . 2 3})$ & $0.14(0.06,0.23)$ \\
International & $0.31(0.24,0.40)$ & $\mathbf{0 . 3 0}(\mathbf{0 . 2 3 , 0 . 3 8 )}$ & $0.30(0.23,0.38)$ \\
\hline
\end{tabular}

(ii) With autocorrelation

\begin{tabular}{lccc}
\hline Seasonal growth res. & No regressors & An intercept & A linear trend \\
\hline National & $0.46(0.26,0.70)$ & $\mathbf{0 . 4 6}(\mathbf{0 . 2 6}, \mathbf{0 . 7 0})$ & $0.46(0.25,0.71)$ \\
International & $0.60(0.44,0.85)$ & $\mathbf{0 . 6 0}(\mathbf{0 . 4 2 , 0 . 8 2 )}$ & $0.60(0.42,0.82)$ \\
\hline
\end{tabular}

Note: The values are the estimates of $d$ using Robinson (1994). Those in parenthesis are the $95 \%$ confidence bands, and in bold, the selected models across the deterministic terms.

\section{Discussion and conclusions}

The stochastic properties of the time series referring to the number of tourists in Spain have been investigated in this work, separating them between national and international visitors. For this purpose, we have used techniques based on fractional differentiation, which is a methodology that allows us to examine the degree of persistence of the series in a more detailed way than the classical methods that simply distinguish between stationarity $\mathrm{I}(0)$ and nonstationarity $\mathrm{I}(1)$ cases. Seasonality and trends are also taken into account within this framework of fractional integration.

The first noticeable feature in this article is that seasonality matters in both cases, being more important in the case of international visitors. The reasons that explain seasonality in tourism demand are well documented, including climate, institutional reasons such as school or calendar holidays, lifestyle, or special events (Baum and Lundtorp, 2001; Cuccia and Rizzo, 2011; KoenigLewis and Bischoff, 2005; Rosselló et al., 2004; etc.). Seasonality is a distinctive feature of global tourism. However, it is particularly strong in the case of Spain where tourism for leisure and vacations - mostly during summer time - represents more than $85 \%$ of international tourist arrivals (FRONTUR, INE), compared to only $50 \%$ in Europe (EUROSTAT, 2019) or 56\% worldwide (UNWTO, 2019). Moreover, tourism seasonality has a negative effect on the labor market through directly increasing temporary employment, which in the case of Spain accounts for about $26 \%$ of total salaried employment (INE, 2019), the highest in the European Union. In addition, seasonality causes that some infrastructures are created whose potential is underused during off-peak seasons, therefore causing efficiency losses or difficulties for businesses to adapt to changes in demand. Indeed, Spanish hotel chains soon became aware of this issue, and accordingly pioneered internationalization in the early 1990s - first toward the Canary Islands and then to the Caribbeanwith the objective of compensating for the seasonal variations of tourism demand and, therefore, of their turnover. As in the case of private actors, policy makers in Spain should also be particularly concerned about the seasonal variations of tourism flows when designing and implementing policies, especially those targeting international tourists whose flows are the most affected by seasonality.

Moreover, using these models that incorporate trends and a degree of fractional integration, the time trend is only significant in case of national visitors, and the degree of persistence, measured in 
terms of the differencing parameter, is much higher for international visitors. Thus, a shock affecting the series will take longer to disappear in the case of international visitors, while in case of nationals, the series will revert faster to its original trend. Therefore, if an external shock happens, policy makers should be aware that some extra policy efforts-including monetary and nonmonetary measures - would be needed in order to recover international tourism flows, compared to domestic visitors.

Based on the high degree of seasonality, seasonal unit root tests were conducted, the results proving that both series contain seasonal unit roots, and testing the order of integration on the first seasonal differenced $(\log )$ series, the results confirm the higher degree of integration (persistence) in that of international tourism. Once more, an implication of this is that, in the event of an exogenous shock reducing tourism in Spain, stronger policy actions must be taken with respect to international tourists since the national series will converge and recover faster. Furthermore, considering that inbound tourism is more volatile, domestic policy measures should also be particularly directed to combat temporal variations in international demand, as mentioned above. That could include stronger policies for promoting alternative models to the conventional sun, sea, and sand tourism, such as gastronomic, cultural, or business tourism, and furthering the promotion of Spain as an attractive destination in off-peak seasons, thus taking advantages of the warm climate all year in coastal areas. Measures to moderate seasonality in inbound tourism seem much needed also considering that expenditure by international tourists visiting Spain is significantly higher than that generated by domestic tourism: according to the Spanish INE, in 2017 international tourists spent in Spain 87 billion euros, whereas domestic tourism receipts accounted for 30 billion euros.

Competition from cheaper vacation destinations, the increasing turbulence in the international economy, as well as the depreciation pressures on the UK pound due to concerns over Brexit, might erode the Spain's leading international position in the near future. Given the importance of international visitors for the prosperity of the Spain's tourism sector, stronger policy measures seem to be needed to face threats and strengthen the competitiveness of the Spanish tourism industry, through enhancing its quality, distinction, and diversity.

\section{Acknowledgement}

Comments from the editor and two anonymous reviewers are gratefully acknowledged.

\section{Declaration of conflicting interests}

The author(s) declared no potential conflicts of interest with respect to the research, authorship, and/or publication of this article.

\section{Funding}

The author(s) disclosed receipt of the following financial support for the research, authorship, and/or publication of this article: Luis A. Gil-Alana gratefully acknowledges financial support from the MINEIC-AEIFEDER ECO2017-85503-R project from 'Ministerio de Economía, Industria y Competitividad' (MINEIC), 'Agencia Estatal de Investigación' (AEI) Spain and 'Fondo Europeo de Desarrollo Regional' (FEDER).

\section{ORCID iD}

Luis A Gil-Alana (D) https://orcid.org/0000-0002-5760-3123

\section{Notes}

1. See Gil-Alana and Hualde (2009) for a review of these models and its application in aggregate data. 
2. This is done by using the $t$-values of the estimated coefficients of the deterministic terms in the ddifferenced series.

3. It is nonparametric in the sense that no explicit expression is presented for the error term, $u_{t}$. See Gil-Alana (2004) for its application in the context of fractional integration.

\section{References}

Abbritti M, Gil-Alana LA, Lovcha Y, et al. (2016) Term structure persistence. Journal of Financial Econometrics 14(2): 331-352.

Al-Shboul M and Anwar S (2017) Long memory behavior in Singapore's tourism market. International Journal of Tourism Research 19(5): 524-534.

Apergis N, Mervar A and Payne JE (2017) Forecasting disaggregated tourist arrivals in Croatia: evidence from seasonal univariate time series models. Tourism Economics 23(1): 78-98.

Assaf A, Barros CP and Gil-Alana LA (2011) Persistence in the short and long term tourist arrivals to Australia. Journal of Travel Research 50(2): 408-414.

Banco de España (2004) Boletín económico. La competitividad del sector turístico. Available at: https:// www.bde.es/f/webbde/SES/Secciones/Publicaciones/InformesBoletinesRevistas/BoletinEconomico/04/ Fich/be0409-art5.pdf (accessed January 2005).

Baum T and Lundtorp S (2001) Seasonality in Tourism. Oxford: Pergamon.

Bloomfield P (1973) An exponential model in the spectrum of a scalar time series. Biometrika 60: 217-226.

Box-Steffensmeier JM and Tomlinson AR (2000) Fractional integration methods in political science. Electoral Studies 19(1): 63-76.

Chen JH and Malinda M (2014) Long memory and multiple structural breaks in the returns of travel and tourism indexes. Journal of Economic and Business 5(9): 1460-1472.

Cho V (2003) A comparison of three different approaches to tourist arrival forecasting. Tourism Management 24(3): 323-330.

Cuccia T and Rizzo I (2011) Tourism seasonality in cultural destinations: empirical evidence from Sicily. Tourism Management 32(3): 589-595.

Cunado J, Gil-Alana LA and de Gracia FP (2005) The nature of seasonality in Spanish tourism time series. Tourism Economics 11(4): 483-499.

Cunado J, Gil-Alana LA and de Gracia FP (2008a) Fractional integration and structural breaks: evidence from international monthly arrivals in the USA. Tourism Economics 14(1): 13-23.

Cunado J, Gil-Alana LA and de Gracia FP (2008b) Persistence in international monthly arrivals in the Canary Islands. Tourism Economics 14(1): 123-129.

Dahlhaus R (1989) Efficient parameter estimation for self-similar process. Annals of Statistics 17: 1749-1766.

Dickey DA, Hasza DP and Fuller WA (1984) Testing for unit roots in seasonal time series. Journal of the American Statistical Association 79: 355-367.

EUROSTAT (2019) Tourism statistics. Available at: https://ec.europa.eu/eurostat/statistics-explained/index. php?title=Tourism_statistics (accessed November 2019).

FAMILITUR. Movimientos Turísticos de los Españoles. Available at: http:/estadisticas.tourspain.es/es-es/ estadisticas/fichadecoyuntura/paginas/default.aspx (accessed November 2019).

FRONTUR. Movimientos Turísticos en Fronteras. Available at: http://estadisticas.tourspain.es/es-es/estadis ticas/fichadecoyuntura/paginas/default.aspx (accessed November 2019).

Gálvez TG, Romero JM and Devesa MJS (2014) Measuring and analysing domestic tourism: the importance of an origin and destination matrix. Tourism Economics 20(3): 451-472.

Garcia-Ferrer A and Queralt RA (1997) A note on forecasting international tourism demand in Spain. International Journal of Forecasting 13(4): 539-549.

Garín-Muñoz T (2011) La demanda de turismo británico en España. Boletín Económico de ICE 3010: 49-62.

Gil-Alana LA (2000) Mean reversion in the real exchange rates. Economics Letters 69(3): 285-288. 
Gil-Alana LA (2004) The use of the Bloomfield (1973) model as an approximation to ARMA processes in the context of fractional integration. Mathematical and Computer Modelling 39: 429-436.

Gil-Alana LA (2005) Modelling international monthly arrivals using seasonal univariate long-memory processes. Tourism Management 26(6): 867-878.

Gil-Alana LA, Cunado J and de Gracia FP (2008) Tourism in the Canary Islands: forecasting using several seasonal time series models. Journal of Forecasting 27(7): 621-636.

Gil-Alana LA, de Gracia FP and Cunado J (2004) Seasonal fractional integration in the Spanish tourism quarterly time series. Journal of Travel Research 42(4): 408-414.

Gil-Alana LA and Henry B (2003) Fractional integration and the dynamics of the UK unemployment. Oxford Bulletin of Economics and Statistics 65(2): 221-239.

Gil-Alana LA and Hualde J (2009) Fractional integration and cointegration: an overview with an empirical application. In: Terence CM and Patterson K (eds), The Palgrave Handbook of Applied Econometrics (Vol. 2). Basingstoke: MacMillan, pp. 434-472.

Gil-Alana LA and Huijbens EH (2018) Tourism in Iceland: persistence and seasonality. Annals of Tourism Research 68: 20-29.

Gil-Alana LA, Mervar A and Payne JE (2015) Measuring persistence in Croatian tourism: evidence from the Adriatic regions. Applied Economics 47(46): 4901-4917.

Gil-Alana LA, Mervar A and Payne JE (2016) Modelling the degree of persistence in Croatian tourism. Tourism Economics 22(3): 655-664.

Gil-Alana LA, Mudida R and de Gracia FP (2014) Persistence, long memory and seasonality in Kenyan tourism series. Annals of Tourism Research 46: 89-101.

Gil-Alana LA and Payne JE (2018) Data measurement and the change in persistence of tourist arrivals to the US in the aftermath of the September 11 terrorist attacks. Tourism Economics 24(1): 41-50.

Gil-Alana LA and Robinson PM (1997) Testing of unit roots and other nonstationary hypotheses in macroeconomic time series. Journal of Econometrics 80(2): 241-268.

Goh C and Law R (2002) Modeling and forecasting tourism demand for arrivals with stochastic nonstationary seasonality and intervention. Tourism Management 23(5): 499-510.

González P and Moral P (1995) An analysis of the international tourism demand in Spain. International Journal of Forecasting 11(2): 233-251.

González P and Moral P (1996) Analysis of tourism trends in Spain. Annals of Tourism Research 23(4): 739-754.

Hylleberg S, Engle RF, Granger CWJ, et al. (1990) Seasonal integration and cointegration. Journal of Econometrics 44(1-2): 215-238.

Instituto Nacional de Estadística (INE) (2018) Spanish Tourism Satellite Account. Available at: https://www. ine.es/ (accessed November 2018).

Instituto Nacional de Estadística (INE) (2019). Economically Active Population Survey. Available at: https:// www.ine.es/ (accessed November 2019).

Koenig-Lewis N and Bischoff EE (2005) Seasonality research: the state of the art. International Journal of Tourism Research 7(4-5): 201-219.

Landaluce-Calvo MI (2017) Enfoque exploratorio multivariante para el análisis de estructuras temporales: una aplicación a la evolución de la demanda turística en España. Estudios de Economía Aplicada 35(2): 465-492.

Lean HH and Smyth R (2008) Are Malaysia's tourism markets converging? Evidence from univariate and panel unit root tests with structural breaks. Tourism Economics 14(1): 97-112.

Lean HH and Smyth R (2009) Asian financial crisis, avian flu and terrorist threats: are shocks to Malaysian tourist arrivals permanent or transitory? Asia Pacific Journal of Tourism Research 14(3): 301-321.

Liang YH (2014) Forecasting models for Taiwanese tourism demand after allowance for Mainland China tourists visiting Taiwan. Computers \& Industrial Engineering 74: 111-119.

Lopez AM, Flores MA and Sanchez JI. (2017) Forecasting of Spanish passenger air traffic based on time series models with aggregated and disaggregated approaches. Estudios De Economia Aplicada 35(2): 395-418. 
Medeiros MC, McAleer M, Slottje D, et al. (2008) An alternative approach to estimating demand: neural network regression with conditional volatility for high frequency air passenger arrivals. Journal of Econometrics 147(2): 372-383.

Nowman KB and Van Dellen S (2012) Forecasting overseas visitors into the United Kingdom using continuous time and autoregressive fractional integrated moving average models with discrete data. Tourism Economics 18(4): 835-844.

Robinson PM (1994) Efficient tests of nonstationary hypotheses. Journal of the American Statistical Association 89(428): 1420-1437.

Rosselló J, Font AR and Rossello AS (2004) The economic determinants of seasonal patterns. Annals of Tourism Research 31(3): 697-711.

Rosselló-Nadal J (2001) Forecasting turning points in international visitor arrivals in the Balearic Islands. Tourism Economics 7(4): 365-380.

San Román E (2017) Building Stars. Miguel Fluxá. An Entrepreneurial Story. Madrid: Iberostar Group.

Schmidt P and Phillips PCB (1992) LM tests for a unit root in the presence of deterministic terms. Oxford Bulletin of Economics and Statistics 54: 257-287.

Song $\mathrm{H}$ and Li G (2008) Tourism demand modelling and forecasting: a review of recent research. Tourism Management 29(2): 203-220.

Tang CF (2011) Old wine in new bottles: are Malaysia's tourism markets converging? Asia Pacific Journal of Tourism Research 16: 263-272.

UNWTO (2014) Glossary of Tourism Terms. Available at: http://www2.unwto.org/ (accessed December 2014).

UNWTO (2018). Tourism Highlights. 2018 Edition. Available at: http://www2.unwto.org/ (accessed December 2018).

UNWTO (2019). Tourism Highlights. 2019 Edition. Available at: http://www2.unwto.org/ (accessed December 2019).

Vallejo-Pousada RV (2013) Turismo y desarrollo económico en España durante el franquismo, 1939-1975. Revista de la Historia de la Economía y de la Empresa 7: 423-452.

Yaya O, Gil-Alana LA and Carcel H (2015) Testing fractional persistence and non-linearities in the natural gas market: an application of non-linear deterministic terms based on Chebyshev polynomials in time. Energy Economics 52: 240-245.

Zivot E and Wang J (2007) Modeling Financial Time Series With S-Plus ${ }^{\circledR}$ (Vol. 191). Berlin: Springer Science \& Business Media.

\section{Author biographies}

Luis A Gil-Alana is a Faculty Fellow of the Navarra Center for International Development and Professor of Econometrics in the School of Economics and Business Administration at the University of Navarra, Pamplona, Spain. He completed his PhD at the London School of Economics, LSE, in 1997, in the area of Econometrics and Quantitative Methods. He obtained the Ely Devons Prize in Econometrics at the LSE in 1993. He has published extensively in theoretical and applied econometrics and also in macroeconomics, finance, and many other disciplines including climatology, tourism, economic development, and energy and environmental issues.

Águeda Gil-López is an assistant professor of Economics at Francisco de Vitoria University (Madrid, Spain). She obtained her PhD from Complutense University of Madrid. Her research interests include the fields of business history, history of tourism, family business, and entrepreneurship.

Elena San Román is an associate professor of Economic History at Complutense University (Madrid, Spain), and an associate member of the Spanish Royal Academy of History. In 2012, she was appointed as Honorary Researcher at Lancaster University (United Kingdom). Her research interests are focused on business history, history of tourism, family business, entrepreneurship, and international business in the 20th century. 